\title{
The Reform of Computer Professional Hardware Courses Experiment Teaching System and Content
}

\author{
Yongxian Jin \\ College of Mathematics, Physics and Information Engineering, Zhejiang Normal University, \\ Jinhua Zhejiang 321004 , China
}

\begin{abstract}
The computer professional is an excellent major which reflects on the practice. To cultivate talents who of innovative abilities which are in line with the requirements of the era, strengthening experiment teaching and practice teaching is particularly important. What's more, it is most important to establish a reasonable experiment teaching system and teaching content which accord with the cognitive law of college students.Analyzes the problems existing in computer professional hardware courses experiment teaching system and teaching content. And then, we talk about the idea of the reform of experimental teaching system and teaching content. Finally, it expounds the guarantee measures and countermeasures of reform.
\end{abstract}

Keywords- experiment teaching; innovative education; reform;computer professional; hardware courses

\section{INTRODUCTION}

The 21 st century is the era of knowledge economy, it has become a consensus that knowledge-based economy calls for creative talents[1-7]. Thus, the creative education and cultivation of innovative talents have attracted wide attention, and how to build a knowledge-based economy to adapt to innovative education system has become an important issue that all colleges and universities are exploring for. Innovation education is the new requirements based on the development of science and technology, social progress and construction of modernization that are put forward for talents[8-9]. It is aiming at cultivating well-rounded and high-quality talents who have innovative thinking as well as inventive ability and creative personalities. That is to say, experiment teaching is an essential part of creative education; we should put the lab work, laboratory construction and experimental teaching reform to a very high degree to understand the creative education in the new century[10] .

\section{II.PROBLEMS IN COMPUTER PROFESSIONAL HARDWARE} EXPERIMENT TEACHING

Higher Education has been more focused on theory teaching than practice teaching for a long time that results in experiment teaching in the subordinate status. In computer professional, for example, the disadvantages of computer hardware experiment course mainly reflect on that experiment course which based on respective is set up separately and divided and independent relatively. Besides, some hardware experiment projects take such a long time that the students can't participate in the whole process of experiment or make the works of hardware themselves due to the limitation of the time. What's more, due to the subordination of the experimental teaching, hardware experiment teaching has no independent and scientific evaluation system that it is unable to fully mobilize the initiative of students. As a result, there is a widespread phenomenon that students pay more attention to theory than experiment, Furthermore, laboratory should be the important base which cultivates the high-quality and innovative talents and we need high-quality laboratory managers because of the serious shortage of personnel who have practical abilities in high title and have been highly educated.

\section{CONCEPTION OF REFORM}

\section{A. Construct experimental teaching system exists with theoretical teaching}

In order to meet the needs of the experiment course personnel training in the new century, we must break through the traditional experimental teaching mode, so experiment teaching has validated, comprehensive and explore three functions. The computer professional belongs to engineering professional whose main courses of professional hardware have an interrelated and interdependent relationship obviously. Actually it is the relationship between the former and the subsequent lessons, such as electronic technology and computer composition principle is former lesson of Microcomputer principle and interface technology and this is the latter lesson of Single chip microcomputer, embedded system and so on. Therefore hardware experiment teaching can be divided into three pieces which are having a understand of the experiment (familiar with various instruments and experimental equipment) having basic experiments or verification experiments, and the time of which is based on class 
time per course; having individual design experiments and comprehensive designed experiments are arranged in the sixth or seventh semester which would pay attention to the constantly progressive in the teaching.

\section{B. Construct a new experiment teaching content system}

Reform of experiment teaching content system is a systematic project that we have to deal with the relations between experiment teaching content system and cultivation of personnel and theoretical teaching system and experimental methods. In the construction of new computer hardware courses experiment teaching system, reform of experiment teaching content must be carried on and the whole experiment teaching content system should be optimized that make innovate consciousness and abilities of experiment throughout the whole process of experiment teaching. Integrate instead of combination. Reconstruction of experiment teaching content system does not rearrange at all but innovate based on inheriting traditional content. Through integrating the original hardware experiment curriculum and realizing the optimization of hardware experiment teaching content system which including the following methods of integration:

(1) Delete the projects whose contents are obsolete, outdated and have nothing to do with or little relation to the goal of training.

(2) Merge the projects whose contents are repetitive or similar and enrich the experimental content.

(3)Reduce the proportion of verification experiments; increase the proportion of the individual design of experiments and the experimental project which are advanced; and increase the comprehensive design experiment projects which combined with engineering, so that the restructuring of experimental teaching content system would become a relatively independent of the complete system, have an obvious progressive relationship and reflect the characteristics of the times and the spirit of innovation.

(4) Experiment projects should be "fewer but better". The project should not be too much and strengthen the strength of each experiment for improving the qualities of experiment teaching. Especially graduation design, arrange comprehensive designing experiments which combined with practical engineering and further improve the experimental skills and abilities of taking the advantage of experiments to solve practical problems.

(5) Experiment teaching content system also should comply with basic law in education which begins from the shallower to the deeper and step by step. But for the relatively independent experiment teaching content system, there is something inevitable happened that part of experiment teaching contents are set up in front of theory course which leave out some untouched questions for students to solve through study, analysis and exploration. It is necessary to cultivate such abilities in the university and this also accords with people's law of cognition.

(6) In combination with unity and diversity. The significance of reform of talent training mode is to strengthen the students' quality education, especially cultivate those abilities including innovation and practice, which promote the development of students' personality. We set up compulsory and elective experiment projects in the new experiment teaching content system in order to meet the requirements of unity and diversity.

\section{C.Content of specific implementation of reform}

Reform of experiment content is fundamental. Experiment content is a concrete manifestation of the purpose and effect of experimental teaching, reform of content is the key in experiment teaching reform. In combination with the teaching content and the requirements of course system reform plan closely to carry out the spirits of individualized teaching in accordance with their aptitude based on the target of the talent training. We can take four aspects into consideration about the reform of experiment content.

(1) Strengthen basic skills training. Practice has proved that student basic skills training did not get attention in the past, so it is extremely necessary to set up experiment content of systematic basic skills training. The key point is to let the students master the performance, operation and method of test about the experimental apparatus equipment and test tools which commonly used.

(2) Set up individual design experiment. Firstly, teachers will protocol the topic content and propose requirements according to the course or requirements of majors. Then students design the plan and operate independently, and finally, they write the report of experiment. There is no doubt that the way of experiment play a positive role in cultivating not only the abilities of analyzing and solving the questions but also theory with practice and innovative consciousness.

(3) Set up comprehensive experiment. Setting up comprehensive experiments whose content would reflect integration of multi-hardware course. Experiment content should take the continuity of knowledge and innovation into consideration that would create the space for students to solve the engineering practical problems, and pay attention to combined theory with practice and comprehensive utilization of knowledge, give the students more bounteous time and leave room for thinking. The experiment is beneficial to inspire students' thirst for knowledge, desire for exploration and sense of success that the initiative and enthusiasm of learning and research would be fully mobilized.

(4) Set up scientific research experiments. 
Conditions need to be created for students to search for more opportunities to open up research activities. Students could conduct some scientific research experiments under the guidance of the teacher according to their thinking of scientific research. It has a positive role in promoting students' development of individual character, cultivation of innovative consciousness and abilities of scientific research.

\section{SAFEGUARD MEASURES AND COUNTERMEASURES}

\section{A. Vigorously promoting the construction of experiment teachers'team}

The purpose of the experiment teaching reform is to improve the quality of experiment teaching and to train high quality constructive personnel for the country. In order to achieve this goal, we must have a high-quality experiment technology team which has reasonable structure, consolidating foundation and excellent skills. It is the reliable guarantee that the experiment teaching reforms can be going on smoothly.

(1) Strengthen the education of professional ethics. Experiment technician should pay more attention to the improvement of ideological and moral qualities and define their responsibilities and obligations in experiment teaching. Not only should they have profound theoretical knowledge and excellent skills, but also must have some codes of conduct such as dedication, being passionate in their jobs.

(2) Improve the professional qualities of the laboratory technicians. Experiment technicians should not only have a noble professional ethics and strong capabilities of management, but also have rich technical reserves and excellent skills. Through the study and planned training they can strengthen the theoretical basis, broaden the professional knowledge, have a good knowledge of modern scientific technology and information technology and improve their own professional quality constantly, so as to adapt to the requirements of the development of science and technology and the reform of experiment teaching.

(3) Adjust the whole structure of the experimental team. In the structural adjustment, we should pay more attention to the optimized combination of professional knowledge and educated structure. According to the characteristics of majors and subjects, we can pick out and train a group of academic leaders and experimental technology backbone to give full play to their talents.

(4) Formulate relevant policies to attract young teachers into the lab and participate in laboratory construction. For example, the young teachers would be required to exercise for a period time in the lab, and if they make some achievements in the laboratory construction they would be given priority to promotion. These policies can not only relieve the situation about the shortage of laboratory personnel, but also be beneficial to the teachers' practical ability and the development of the laboratory construction.

\section{B.Adopting opening experiment teaching method}

The reform of experiment teaching contents must be combined with the reform of experiment teaching method to train students' practical ability and inspire their innovative consciousness in all aspects of the experiment teaching at all levels. Finally, the experiment teaching changes from traditional mode of "teacher-centered" into the mode of "student-centered, teacher-led". It will adopt an opening experiment teaching to let students have more time to take part in the whole process of experiment and hardware work. Hardware experiment projects or work need a long time that students can't personally participate in experiments because of the limit of arrangement experimental time in class, which make a serious difference in the experimental results. Opening laboratory is the only way to reform of hardware experiment teaching.

\section{Improving experimental methods of guidance, strengthening training of abilities}

According to the aforementioned hardware experiment teaching content level of progression, we can adopt various methods of guidance. For having a understand of a experiment, in order to make sure students obtain the operations of instrument and basic training of experimental skills that experimental teachers need to explain the principle, method of operation, matters of attention and give demonstration operation of conventional instrument. For verifying an experiment, we should provide students with enough experimental time, and the teachers are just playing a role in tutorship that they pay attention to observing the process of experiments when they find and solve the difficulties which students meet. It is helpful for individualized education and key guidance that make different levels of students can get training and development. For individual design experiment, it can be alternative that teachers pick out the subjects what are flexible or students select the experiment contents and design the experiment. Before the experiment, teachers strengthen discussions with students about experimental program and experimental methods that the important part of the experiment which is implied would not be overlooked. It is beneficial to cultivate innovative consciousness of students. In the process of the experiment, teachers ask targeted questions to arouse the enthusiasm of independent thinking and develop the initiative of students. In addition to open part of individual design experiment, we should also open a comprehensive design experiment combined with scientific research work and graduation design that can cultivate students' innovative consciousness, abilities of analyzing and solving problems. 
D. Computer hardware experiment sets up as the lesson alone and individual assessment

It is beneficial to manage experiment teaching and strengthen the effect of experiment teaching after establishing an independent hardware experiment teaching system. Also, we should evaluate their scores according to the requirements and performances of the experiment teaching upon the completion of the above experiment in each stage. As a result of strengthening the evaluation of experiment teaching, students' autonomy and initiative of students are inspirited.

\section{REFERENCES}

[1]Xia You-wei,Cultivating practical ability and creating innovative talents[J].Research and Exploration in Laboratory,2014,33(12),1-4.

[2]Xia You-wei,Cultivating practical ability and creating innovative talents $(2)[J]$. Research and Exploration in Laboratory, 2015,34(1),1-4.

[3] Liu Yongmei, Reform of experiment teaching and cultivation of innovative talents $[\mathrm{J}]$. Experimental Technology and Management, 2005, 22 ( 12 ) : 102-106.
[4]Liu Jinnan,Laboratory's role is infiltrating Universities' functions[J].Research and Exploration in Laboratory,2010,29(6),1-4.

[5]Wang Yujun,Wang Hailing,Technical platform of coordinate LAN in open-type experimental teaching $[\mathrm{J}]$.Research and Exploration in Laboratory,2011,30(6),6-8

[6]Li Yinman,Zhang liqun,Research on normalizing the experimental teaching .management in new stage[J].Research and Exploration in Laboratory,2010,29(6),7-9.

[7]Mao Fanhai, Zhu Linjian, Sun Shoulin. Reform of experimental teaching content and teaching students innovative ability [J]. Experimental Technology and Management, 2005, 22 (4 ) : 88 -90 .

[8]Sun Chuansong. The scientific development concept to guide laboratory building $[\mathrm{J}]$. Research and Exploration in Laboratory , 2005, 24 (9) : 1-3.

[9]Fang Zhenzheng. Laboratory building should have new ideas [J]. Research and Exploration in Laboratory , 2005, 24 (5) : 1-2.

[10]Zhu Yaping,Yu Zi,Strengthening the management of items and increasing the benefit of lab[J].Research and Exploration in Laboratory,2004,23(6),93-95. 